\title{
Against liberal pluralist political practice in South Africa
}

\author{
Pieter Coetzee \\ Department of Philosophy \\ University of South Africa \\ PRETORIA
}

\begin{abstract}
Against liberal pluralist political practice in South Africa

In this article I take issue with liberal pluralist political practice in South Africa. Multicultural civil society requires the recognition of cultural categories which modernity, in the shape of liberal pluralism, cannot accommodate and therefore ignore in the interests of fostering a single monocultural politics. In South Africa this trend has taken the usual route of difference-blind, assimilationist political programmes aimed at nation building (under the slogan "one people - one nation"). I attempt to show" that liberal pluralist practice can be adapted to make space for culiural and ethnic categories, and that a nation of a common political identity can be constructed out of this adaptation, but that a re-interpretation of liberal notions of liberty and equality is required.
\end{abstract}

\section{Stating the problem}

The political process in South Africa today is dominated by liberal pluralist thinking. South African liberal pluralism, however, assumes Euro-American value tenns and working conditions which, as liberal procedures standardly do, tend to screen out the diversity of cultural viewpoints and conflicts, thus prejudicing the South African political culture to a politics of difference, the very thing which a multicultural reality seeks to affinn. It is a striking irony that the categories of difference (and identity) which the apartheid era had so prejudicially affirmed in favour of whites, particularly with respect to citizenship (and, by implication, negated for blacks) once again disappears under the weight of political expediency. This is a different form of what, during the apartheid era, might have been called an "uneven deployment of identity politics" (Goldberg, 1994:110). A number of identity struggles arising from notions of difference are challenging the established norms of liberalism's attempt to foster a single political culture. This challenge is really about unrecognized assumptions in the liberal programme about how a multicultural civil society operates, a reminder that the discursive space within which a multicultural critique might grow has to be recognized as part of the social conditions of a democratic culture. 
The culturalism of modernity relies on a civil-society tradition, one which includes the practice of contested dialogues as the main mechanism through which political disputes are settled. The growth of this tradition in South Africa since the demise of apartheid has been characterized by the difference-blind fashion in which liberalism standardly treats certain items on the agenda of the public dialogue. This means that the notion of a contested dialogue has operated only within a space constrained by the things which are excluded - things like the impact of culture and ethnicity on the process of nation building. These things would - if recognized - transform the civil society matrix to reflect a politics of difference centred in civil groupings seeking identity through self-definition in the political institutions made available by the liberal constitution.

The politicization of the public sphere and of the critical discourse which has recently grown in this arena is, of course, an ideal of pluralist programmes; this is to protect a multiplicity of cultural spaces from the power of the state and from assimilation by dominant cultures. But politicization of the public dialogue in South Africa has thus far proceeded without any significant attempt to contextualize the debate in cultural and ethnic realities, though the nation-building rhetoric currently in vogue has strong nationalist overtones. This smacks of ideological orthodoxy (no doubt a consequence of apartheid's painful legacy), and is self-defeating in two important senses: it tends to blur the distinction between state and civil society (another irony, for the failure to make the distinction was part and parcel of the apartheid regime's ideological commitments), and it blunts the edge of critical theory - an edge which, in Goldberg's turn of phrase ".. depends on the national and institutional sites that constitute the horizons of practice ... [M]ulti-cultural linkage of criticism requires comparative contextualization ... [i.e.] sources in multiple cultural contexts so that the critical tools used as a wedge into understanding the production of norms themselves would become objects of scrutiny" (Goldberg, 1994:120)

The dependence on culture as a context for criticism should itself always be the subject of critical inquiry, for this guards against forgetfulness about how Western pluralist concepts are received and read in African contexts. A critical multiculturalism necessarily seeks "alliances of differently contextualized critique" (Goldberg, 1994:121) as a bulwark against assimilation of differences by liberal cultures and the marginalizing effects of this process (the consequences of liberalisms' failure to acknowledge culture and ethnicity as epistemically viable categories of difference). The critical import of such alliances is manifested in the challenge offered to the alleged universals of liberalism's discourses, particularly those advocating tolerance (of differences) and empathy (for minorities), founded on a concept of a common humanity.

Goldberg's point about the treatment of difference in "comparative 
contextualization" can be made as a question about the starting and endpoints of critique. One must " start from local critiques and then derive a larger picture of what critique would mean when articulated from different positions" (Goldberg, 1994:123).

The recognition that cultural differences are a source of critical force is really only useful if the public sphere is truly an unconstrained space, one in which a variety of identity struggles can be brought into "comparative relation" (Goldberg, 1994:124) without the threat of assimilation and marginalization. In this context the critical force of the notion of difference retains its edge, which is easily lost when culture is understood as a site of shared or common understandings, a point which the "nation building"-rhetoric in South Africa exploits. The notion of a critical edge which a comparative relation of alternative points of view makes possible is captured in the idea that "... different cultures ... have quite different uses for the same theory - or the same history" (Goldberg, 1994:121).

It is possible to argue that from non-colonial perspectives of otherness, the history of South Africa could be put to a variety of critical uses, one of which would be the creation of non-colonial spaces for an encounter with liberal histories. Such an encounter would impart a critical edge to the notion of difference, one which could lend epistemic credibility to the otherness of alternative viewpoints. The critical potential of an encounter between the different histories of South Africa lies in the fact that they make available perspectives of otherness. Liberal histories (for example The Oxford history of South Africa edited by Monica Wilson and Leonard Thompson) bear witness to anthropological categories of cultural difference (the influence, no doubt, of Malinowski and other structuralists), articulated as local, community-based "native" perspectives, written from the viewpoint of liberal individualisin. This viewpoint, however, blocks from view the very political conditions needed to account for the existence of "native" perspectives, conditions which non-colonial histories would be able to exploit as critical tools to rescue the "identity" of the post-colonial subject from essentialism, to show that these subjects are time-bound social/historical constructions and to critique them and their "native" predecessors as such. Given Goldberg's "comparative" approach such an encounter would amount to a deconstruction of time-bound social and cultural constructions - a levelling of the playingfield for both "natives" and "colonists".

The anthropological categories of cultural difference which existed within the framework of liberalism aided a discourse of domination during the colonial epoch. In South Africa today liberalism continues to dominate through its assimilationist mode of operation. The way in which liberalism recognizes "difference" brackets all that forms part of the substantive social life of 
individuals: assimilation operates through the non-recognition of the Other in her historical or cultural setting. Civic community is conceived homogenously and monoculturally in the interests of fostering the "one-nation-one-people-one culture" idea of democracy. In this sense liberalism is a reactionary force.

The culturalism of modernity ceases to be culture if civic communities can be admitted to civil life only in some trunctuated form, stripped of the particularity of their historical and cultural settings which give substance to their social identities. Trunctuation creates problems of self-understanding and self-definition in political life, the very context through whose agency these things are actualized.

\section{The political incompetence of the culturalism of modernity}

\subsection{The discourse theory of culture}

Habermas's comments on culture form part of his attempts to work out a critical theory of society. The main theme of Habermas's involvement with culture appears as a critique of capitalism. Pusey (1987:199) describes it as "an attempt to recover from the system of exploitation inherent in capitalist production a potential for rational reconstruction and development of society, which reconstruction would, because of the stress on reason, have emancipatory potential for society".

\subsubsection{Reason and emancipation}

Habermas's involvement with reason is the foundation on which he constructs a theory of culture. Habermas is intent on uncovering ideologies which inform a community's self-understanding and linking them to forms of culture which have potential for emancipation. This, in effect, is a quest for the rational emancipation from ideologies which encourage domination and submission as the pattern or governing principle of interaction in society (Pusey, 1987:194-209).

How does Habermas conceive of reason's emancipatory function? Briefly, like Marx, Habermas believes that the capitalist mode of production harbour on elitist ideology which, in effect, manipulates both majoritarian and consensual (pluralistic) forms of democracy. Market relations between wage-labour and capital form the basis of exploitation and domination, which is made possible by a social organization geared to the demands of capital accumulation. Capital accumulation as a structuring or governing principle of society has to be replaced by a different principle of social organization, one geared rationally to the satisfaction of human needs as the primary objective. A labour theory of culture, of the kind Marx produced, cannot provide the desired principle. The reason is that Marx reduces all patterns of social interaction to labour. This kind of (economic) reductionism identifies social integration (the process of socialization) 
Pieter Coetzee

too closely with production, technology and instrumental (technical) knowledge a focus too narrow for Habermas. For Habermas socialization and production are distinct processes, and though both have a place in Habermas's social order, only socialization properly admits of rational justificatory procedures which create the kind of socio-cultural structures that have emancipatory potential (Sensat, 1979:55-77). Following Sensat (1979) this thesis distinguishes between normative structures that link in a Marxist way to economic systems, and normative structures that connect, in the way Habernas wants, with the "cultural" - a Lebenswelt which reason might shape in accordance with human needs.

Normative structures linking with economic systems are external to the individual - a self-contained lifeworld which can be separated from individual consciousness. Normative structures linking with culture are internal to the individual, in the sense that those structures make up a lifeworld out of which the individual cannot step. This separation gives to reason considerable power to generate a critique of society, in particular, a critique of exploitive economic systems like capitalism. This separation also allows Habermas to separate notions of autonomy and identity from a determinist basis in economics, in a way in which Marx could not. But, though normative structures are separated, they remain tied to each other: the normative structures of culture are "superstructural" (Pusey, 1987:198), and this means that culture is a superstructural phenomenon, resting on the normative structures of socio-economic systems. So Habermas's separation is not complete - economic structures condition cultural structures, though they are not the only factors at play; rational justifications of normative structures and rationally secured social agreements are as important. Culture has to be understood as rational social action - it is a rational form of communicative action. The idea of culture understood as communicative action is very simple culture is something subjects or agents create, in thought and deed with the help of reason, guided by the normative structures of particular socio-economic systems.

It is apparent from what has been said that Habernas gives considerable normative force to rationality. Rationality is understood not only as purposive or instrumental - as having structure-forming power in so far as it creates cultural structures. It also has intrinsic value understood as emancipatory potential, which is value in itself. In this regard rationality mediates all social relations, and to do this it must necessarily be embedded in the common or shared understandings of a community, as contained in its various self-understandings. Thus understood rationality is "linguistically mediated social interaction" (Pusey, 1987:199), which includes a critical component: a power to restructure society along rationally agreed lines. This critical component is its "emancipatory potential" (Pusey, 1987:199). This is just rationality understood as a property of human thought and 
Against liberal pluralist political practice in South Africa

language - a quality directed to asking and answering questions about human needs and the social conditions required for their fulfilment.

\subsubsection{History, reason and legitimacy}

\subsubsection{The public and private spheres}

The rise of the modern era was marked by the following:

- the separation between the "public" and "private" spheres (or between "civil" and "civic" society),

- the development in society of the idea of agency rights, and

- finally the development of the idea of a public forum of discourse (or public discursive space) which served as the arena within which opposing moral and political views could be debated.

It is possible for societies to particularize by making use of a range of informal interpersonal practices, created through conflict between the needs of agents to pursue local goals and a communual need for basic collective solidarity 1 . Individuated public spaces - whether individuated through commerce, science, religion etc. - form civic societies; collectively they form civil society. Civic society permits the growth of various solidarities among interest groups, usually in opposition to the established civil authority. Civil society is best understood as an institutionalized correlate of the political authority, and cannot be defined in terms which express opposition to the state. Civic society, by contrast, is a form of social organization embedded within civil society acting as a countervailing force to civil society.

Civic society becomes the arena in which the values of various interest groups are confirmed. Since civic society is managed by interest groups, the public spaces generated are small enough to permit social meanings and their interpretations to be contested and rewritten. Autonomy is protected by the fact that the boundary between civic and civil society creates a legitimate private realm, which, by virtue of its oppositional nature, could engage in critical dialogue with the public (civil) realm.

Generating consensus or agreement through the contested dialogue of a public debate has a significant spin-off. Thus conceptions of the good life are privatized (within a civic grouping) before being pushed out onto the agenda of the public dialogue, where they compete for legitimation. No belief to which anyone may

For my understanding of the "private-public" distinction I am indebted to Buchowski (1979) 
be deeply committed - such as the belief that a sexual division of labour is morally wrong because it oppresses women and hinder their attainment of personhood - can be excluded, and so no-one is prevented from seeking the widest possible forum to arrive at a consensus. The contested dialogue of a public debate renegotiates and redefines the boundary between "private" and "public", since it helps to define the nature of the issues that get pushed onto the agenda of the public dialogue and since parties discover what their deepest disagreements or agreements are, only once the process of public dialogue has run its course. Benhabib (1992:100) notes that struggles to off-set the effects of power differentials in any context begin with a redefinition of what had previously been considered "private" (such as all matters relating to the household), and therefore not matters of public concern (i.e. not matters for debate on a public agenda). This flexibility in a society to (re)negotiate the boundary between "private" and "public" cannot be frozen as long as it is pennissible to question the rules of participation in the dialogue. This means that the boundary cannot be redrawn in such a way that it limits the reach of moral particularity of civic society into civil society. A consequence of this is that the boundary cannot prevent privately held values from becoming public shared norms, and therefore that it cannot limit civic autonomy. Indeed, where the boundary is drawn is a matter for negotiation and rests ultimately on consensus

The picture that emerges here is that of bourgeois culture and society in which a "procedural type of legitinacy" becomes the norm in moral and political matters. Habermas (1979:184-185) says:

The formal conditions of justification themselves obtain legitimating force ... the level of justification has become reflective and the procedures and presuppositions of justification are themselves now the legitimating grounds on which the validity of legitimations is based. The idea of an agreement that comes to pass all parties, as free and equal, determines the procedural type of legitimacy of modern times.

\subsubsection{Agency rights}

How did "the procedural type of legitimacy" manifest itself in society? If Habermas is right, the procedural republic developed in the wake of the failure of ontologically grounded justifications (God or nature) and became the proper setting of justification by consensus (Pusey, 1987:194). Two developments in this regard are of special significance.

- Because society has become culturally pluralistic, it becomes necessary to create scope for differences between individuals and groups which are to be integrated in social structures. 
- The resolution of conflict between culture and social integration takes the form of a reordering of social relationships. The idea of a fixed, invariant conception of justice is confined tn a public sphere in which the political authority of the state is limited, and in which relations between individuals are subject to principles secured by rational agreement. Beyond this sphere, individuals are free to pursue their self-chosen ends and goods. This is the civic space referred to above - within it people are free to follow diverse values and interests without having to secure the approval of others and without having to suffer legal liabilities for their choices.

Central to this conception of public space lies a conception of human beings as agents whose agency has cash-value in society because the purpose of agency social integration - is culturally anchored ${ }^{2}$. The social nature of our agency determines that we think of ourselves as social constructions whose hopes of a shared, just society can be realized in the promise of social solidarity which only culture can offer - and this is because the cultural is irreducibly collective. Now, the link between agency and rights is a social given. Indeed, it is a function of the split between "public" and "private", which created the need for private space in which agents may act autonomously, and the need for state protected space in which an ongoing debate about the basic structure of society may continue. In this context rights can only be defined with reference to agency. This has a major effect on social integration, but one which enhances the potential for autonomous action. The scope of the political authority becomes limited to enforcing only those rules or norms which participants in the discursive space accept as rationally binding on all. These rules protect the private and autonomously chosen space of individuals and groups to pursue their own distinctive ends. Human agency, then, provided a conceptual basis for a system of rights - in particular, agency rights, because they recognize and create scope for the exercise of human capacity for agency.

To treat someone as an agent is to treat her in terms of her capacity for agency. At a minimum this means treating her as one capable of autonomous choice, or as one capable of choosing on the basis of reasons. How autonomous are these reasons? Habermas's discursive public space is the sociological correlate of his discourse concept of legitimacy - it is the arena in which dialogues of legitimacy take place and legitimacy is confirmed (Benhabib, 1992:103). Habermas views this space democratically as the space in which the rules of participation and procedures are open to reformulation and reinterpretation by those who participate. This space, then, does not stand under the constraints of neutrality i.e. the rule which govern the dialogue does not pretend to be neutral between 
competing conceptions of the good which enter the dialogue, but are rather themselves written in terms of these conceptions whenever a dialogue takes place (Benhabib, 1992:105). The public sphere can be any discursive space and comes into existence whenever and wherever parties engage in discourse, evaluating the general social and political norns which govern their society. There may be as many public spaces at any given time as there are debates about the validity of social norms. And these are autonomous public spaces or spheres, making for a plurality of viewpoints, a fact which greatly encourages the democratization of civil society.

The autonomy of each space in this plural landscape is substantive and not merely formal. Thus, though the autonomy of each space is subject to the constraints of a practical discourse in which the criterion of what counts as a good argument depends heavily on shared meanings and practices that make up the communicative structures of everyday life, each space may legitimately legislate on substantive nonnative issues. Normative issues include the following consensual generation of norms in debates which challenge tradition, the development of individual identities outside conventional role and gender definitions as well as the relevance of cultural tradition for self-definition. The mentioned cultural tradition for self-definition has been becoming increasingly autonomous i.e. dependent on individuals' reflective and critical abilities rather than on rigid role understanding or the appropriation of exemplars from history. The main problem in mediating relations between civic and civil society is not so much to persuade rational agents that they should accept the moral constraints of their forum, but rather to create a culture of discourse to mediate among opposing moral conceptions of what morality demands of us. The social significance of this issue - its actual manifestation in society - walks hand in hand with the growth of appeal to a rational justification for morality ${ }^{3}$. They are inseparable social phenomena. Creating a culture of discourse is, for Habermas, a strategy for creating a morally just political order.

\subsubsection{Discursive public space}

According to Habermas discursive spaces do not operate under the procedural constraints of neutrality. By this is meant that the conversational constraints set by Habermas's discourse of legitimation reject the claim that any reason for action can be a good reason if it is maintained that this conception of the good is better than those advanced by others. For Habermas the openness (Offentlichheit) of discourse cannot be overridden by "morally neutral" constraints about the way in which discourse must take place. Accordingly, the only constraints 
Habermas recognizes are those which arise from practical discourse itself, and these are specified by the shared meanings and practices that make up the communicative structures of the everyday life-world. These constraints are themselves normative, and take the form of conditions of participation rather than criteria of procedural equality or neutrality. Habermas assumes that at minimum they are conditions of universal moral respect and egalitarian reciprocity, conditions he believes to be compatible with the democratization of society, which he sees as a growth in the plurality of autonomous public (civic) spheres and spaces (Benhabib, 1992:29-31). These constraints, he believes, avoid the problems of elitism and inegalitarianism, working rather for consensus in his vision of a plurality of discursive democracies.

The condition of universal moral respect requires that participants recognize the right of all beings capable of speech and action to be party to the moral conversation. The condition of egalitarian reciprocity requires that every participant in the moral conversation must have the same symmetrical rights to various speech acts, to initiate speech (i.e. the topics of conversation), and to request reflection on the presuppositions of the conversation. The latter, of course, allows that the rules of the conversation game can be contested within the game itself, but only insofar as participants accept to abide by the conditions of participation in playing the game. The rules of the game no less than their interpretation are contestable, but contestation does not mean that they can be rewritten in such a way that the conditions of participation are suspended because this would mean that parties to the conversation enter the dialogue without the required "will" to arrive at consensus

How are these constraints (conditions of participation) of the moral conversation justified? Habermas argues that as rules of fair debate these constraints are "universal-pragmatic" presuppositions (of fairness) which can be viewed as a set of procedural rules (Benhabib, 1992:30). This view, is, of course, standardly liberalist because it embodies the moral ideal that we ought to respect each other as beings whose moral standpoints are deserving equal consideration. This view also implies that we ought to respect each other as human beings whose capacity for expressing a standpoint (communicative competence) we ought to enhance every time we create a discursive democracy (which is wherever and whenever we create civil or civil discursive spaces). There is no justification for these constraints beyond these considerations.

The central question at issue in Habermas's discursive spaces (whether civic or civil) can be formulated as a request for universal moral principles of action: What principles do participants recognize or agree to as being legitimate, given their history and circumstances? This question is, for Habermas, the test of communicative agreement. But, we may ask, agreement in what context? 
- A moral/political landscape with a plurality of discursive democracies Is it enough to achieve communicative agreement in autonomous civic societies? Or must such agreement be strictly universalized across civic boundaries, i.e. must the reach or scope of principle be extended to civil rather than just to civic society? It is instructive to note that for Habermas the conditions of participation are universalizable in the sense that they become intersubjective procedures of argumentation for all civic groupings (Benhabib, 1992:36-37). Any principle of action adopted in a civic grouping can, in principle, not conflict with the conditions of participation, because that would be in conflict with the idea of communicative agreement. Since this idea of communicative agreement defines a weak sense of justification, all principles of action are strictly subject to weak justification. (A strong justification would require that the status of Habermas's conditions as pragmatic universals be dropped.) But within this broad parameter many different agreements are possible. Habermas wishes to retain a moral/ political landscape in which a plurality of discursive democracies are possible. How is this possible?

\section{- Habermas's participatory view of public discourse}

Habermas takes a participatory view - rather than an integrationist one - of public discourse because he sees the problem of modernity as one characterized by a sense of the loss of moral and political agency, particularly the efficacy of agency - rather than a loss of a sense of belonging and solidarity (Benhabib, 1992:77). He thinks that the intersubjective constitution of the self and of selfidentity through communicative interaction are adequately taken care of within civic groupings (which have non-exclusive principles of membership). So he rather wishes to stress differentiation between communicative agreements, and the autonomous status of the discursive spheres within which agreements are reached. Differentiation is, according to Habermas, a force working for the consensual generation of norms because it creates the required social bonds within which decisions can be made regarding the distribution of social goods. This has the significant spin-off that it empowers agents - they create autonomous principles of social life, gaining thereby a sense of agency and efficacy. And since they create these principles autonomously - without the threat of subversion by the civil authority - they are better placed to understand the nature of the social bond which defines their identity and to comprehend its meaning (what it offers them in terms of self-understanding). Democratization which allows tradition to be subjected to critique and revision at the level Habermas thinks is necessary to overcome the alienating conditions of modemity encapsulates something of the integrationist view, but at a level which remains sensitive to the local and the historical. 


\section{- Differentiation as a focus on justice}

Habermas's emphasis on a "participation" understanding of society raises social differentiation to a high level of value. In Habermas, differentiation takes the form of a focus on justice. Judgements of justice constitute the hard core of all (deontological) morality (Benhabib, 1992:72). Because differentiation (and the preservation of autonomy) is so important, Habermas believes that significant work in morality can be done only in the realm of self-other relations, particularly to structure such relations. Indeed, judgements of justice reflect conceptions of self-other relations. The formation of self-identity and justice are therefore linked. Judgements concerning the good life fall outside the ambit of this project because the whole point of structuring self-other relations is to set agents free (i.e. create private space for them) to pursue their choices. In this latter respect the liberties of competent communicators cannot be limited or curtailed for the sake of some specific (substantive) conception of the social good or welfare. So with respect to judgements about the good life, individual rights trump the collective will. But not so with justice. Judgements of justice are the foundation stone of the freedom of civic groupings to reach communicative agreement, and must therefore rest on real/actual discourses (and not hypothetical ones) which take the conditions of participants - their particularity - as a starting point for their dialogue. This means in effect that justification and contextualization in real situations run together. Only those norms can claim legitimacy that meet - or could meet - with the real situations of participants in their capacity as participants in practical discourse.

\subsubsection{Habermasian reactionism}

Does this project succeed? In particular, does Habermas's social order empower agents in the sense that it restores a sense of the efficacy of their agency? And does it encourage the growth of self-identity? Habermas constructs a "superstructural" notion of culture from the idea of a plurality of divergent universes of discourses. But ultimately his concept of communicative rationality - in particular, the pragmatic universal presuppositions of public dialogue - appeal to a notion of cultural unity. This cultural unity requires that all validity claims be redeemable within specific discourses - a culture which also elevates the force of argument to the final court of appeal. So, though Habermas seemingly opts for a participatory approach, his concept of communicative rationality contains within itself an assimilationist ideal which militates against cultural pluralism and the traditionalism of civic groupings. This assimilationist ideal is achieved by promoting a concept of civil community which is both homogeneous and monocultural, and which resists the cultural and ethnic particularity of civic groupings. It is indeed, whatever potential for this kind of particularity exists at the civic level, transformed into a single identity at the level of civil society. Civic community, to have any sense of coherent identity, is likely to fall victim to 
the shared order of being which Habermas's concept of communicative rationality engenders

If all this is correct, the autonomy of criticism (understood as the contested dialogue) easily falls victim to sponsorship and control by the state. Civic discursive spaces cease to be unconstrained spaces which help to shape struggles over self-definition and identity. Indeed, since difference falls victim to the monoculturalism of Habermas's concept of communicative rationality, it is not difficult to see how easily the multiplicity of discursive democracies fall prey to assimilation by a reactionary cultural politics.

\section{Adapting the culturalism of liberalism}

\subsection{Difference versus identity}

Liberal pluralism, in the version defended by Habernas, attempts to derive the effectiveness of discourse as a social critique from a transcendental perspective. This is perhaps the central reason why the critique which communicative rationality generates loses the critical force of the cultural, and thereby whatever force the notion of difference could have. Now, one way of bringing about a reconciliation between the professed ideals of pluralism, and their realization in practice, is through a refornulation of the liberal tradition. This is what Kymlicka (1989) and Taylor (1995) attempt to accomplish.

Kymlicka (1989:162-181) places the cultural and the historical at the centre of an attempt to rehabilitate notions of citizenship and community as the basis for a substantive approach to participation in the liberal democracy. There is a sense in which culture is a determinant of choice.

- First, decisions about ways of life are informed by culture in so far as the range of alternatives is determined by the cultural heritage

- Second, it is only within a culturally specified range of options that we decide which roles to adopt and which ones have value for us

- Third, cultural membership makes these options and our decisions about them meaningful to us.

Taken together, these points suggest that loss of cultural membership is a fundamental loss which affects our capacity to judge the value of our life plans.

Culture is, however, not just a determinant of choice. It is also a determinant of identity. One way of showing a connection between cultural membership and identity is through language. The sociologist, J. Fishman (1972:4), argues that "language is never simply a neutral medium for identifying the contents of our 
Against liberal pluralist political practice in South Africa

activities - rather it itself is content, a reference for loyalties and animosities, a marker of societal goals, the large-scale value-laden arenas of interaction that typify every speech community".

Another way of showing the connection is through history, especially a history of oppression. The South African political activist, F. Mkhwanazi (1985:18), says the following about black oppression and the loss of a sense of personal efficacy: "The regime tried to make us believe that our people had no history ... they wanted us to carry an image of ourselves as pathetic, utterly defeated, dependent, incapable and powerless".

Miller (1989) shows that ethnographers and historians have great power over oppressed people inasmuch as they can fix an identity for them. A case in point is the creation of the Pokomo as a "backward" group in East Africa. A rigid system of colonial control over agriculture constrained and disadvantaged this group through the creation of a "backward" identity, and various stereotypes associated with that identity. A similar theme is evident in the work of the anthropologist Hayt Alverson (1978). Alverson explores patterns of dependency between the impoverished rural Tswana people of South Africa and the labourintensive mining economy in which they strove for self-sufficiency. He articulates this striving in terms of their concept of "wanting-to-do", and shows that the laying of plans for life through culturally recognized work is basic to their selfidentity and that this persisted in the face of dehumanizing work conditions under the migrant labour system. The African historian, Wunyabari Maloba (1993), examines the psychology of dispossession as a cause of the anticolonial MauMau revolt. Dispossession of land led to a complete disjuncture with Mau-Mau history, a break with notions of community as these people understood it, and concomitantly, with their self-identity, which created a trauma about which colonial records have had little to say. All this makes sense on the assumption that personal agency is tied to a cultural heritage, and that a cultural structure imparts a sense of self-identity. The upshot is that since our ability to choose and to actualize our humanity can be developed only in a certain kind of social context we have a duty, and necessarily so, to sustain that context. An empirical fact about the vulnerability of cultural structures - they are fragile and they can be damaged and even destroyed (see Kymlicka, 1989:162-181) - commits us to their preservation.

Contexts of choice and identity are primary goods in Rawls's sense i.e. sustaining a cultural structure is as significant in a just society as protecting liberties and securing conditions of equality of opportunity. Kyınlicka's cultural thesis has a significant spin-off which counterbalances the difference-blindness to which liberalism standardly falls victim. This is why multicultural states need to make provision for differential citizenship rights (group or minority rights) as a 
necessary premise of the equal respect people are owed as members of specific cultural communities. Kymlicka's argument (Kymlicka, 1989:38), which begins with the liberal principle that people are responsible for their choices, though not necessarily for their circumstances, offers as its major premise the view that differences in resources which affect people's choices arise from their circumstances. Unequal circumstances which may inhibit and even penalize participation in the political community constitute an area of illegitimate inequality. A cultural minority, or even a marginalized culture, is not responsible for the disadvantages it suffers in its attempts to maintain its integrity, if those disadvantages are due to unequal social circumstances. Furthermore, the benefits of dominance which accrue to a dominant culture comes without cost to its members, but these benefits are beyond the purchase power of minoritized or marginalized individuals; they have to pay to secure whatever is valuable to their cultural heritage, which leaves them with less resources to pursue other cultural projects. Spending their resources on securing mere survival is not a problem which members of the dominant cultures face - indeed, they get if for free. The minority cultures should then be compensated for their disadvantages by state recognition of special group rights.

It is not difficult to see that the source of Kymlicka's argument for special rights protecting minority and marginalized cultures from the disintegrating and assimilating effects of decisions made by people outside these cultures, rests on the context of identity variant in his argument. A context of choice can be degraded and difficult to maintain because a context of identity is threatened. The unequal costs associated with differential social circumstances, which requires additional (state sponsored) resources to give threatened cultures equal life-chances, should then be justified with reference to the considerations of cultural identity. It is worth noting here that Kymlicka's major objection to assimilationist policies invokes the identity postulate: “... cultural membership affects our very sense of personal identity and capacity ..." (Kymlicka 1989:175).

The identity postulate contains a revisability criterion. “... we lead our life from the inside, in accordance with our beliefs about what gives value to life ... [Yet we must] be free to question those beliefs, to examine them in the light of whatever information and examples and arguments our culture can provide (Kymlicka, 1989:184).

The argument that minoritized or marginalized cultural groups will be handicapped with reference to the primary good of cultural membership by circumstances for which they are not responsible is a variant of the politics of difference, but with strong overtones of an identity politics. (Circumstances which handicap minoritized people and for which they are not responsible should, however, as an imperative of justice, and by special rights, be redressed.) 
Referring to South Africa, Kymlicka remarks that justice is not necessarily guaranteed by a system of plural citizenships and special rights of the kind he is advocating; an appeal to justice (i.e. special rights) is properly called for only for those communities who find themselves in circumstances of cultural vulnerability.

The major problem with this appeal is that it is perceived as violating equal protection guarantees. The major political task, then, "is to devise constitutional provisions ... which will be flexible enough to allow for the legitimate claims of cultural membership, but which are not so flexible as to allow systems of racial or cultural oppression" (Kymlicka, 1989:255)

In other words, though identity variants are critical in that they guarantee a recognition of differences, they must not be so strong that difference is compromised. How this might be practically possible is unsatisfactorily answered by the revisability criterion, for this criterion requires that there should be cultural borders, but does not specify their degree of interrelationability. For Peters (1995:49) such a state of indeterminacy is unsatisfactory. "The deconstruction of the logic of identity reveals how the binary oppositions generated by it [difference versus identity], in fact, require one another for their assertion. A politics of difference, by contrast, unfreezes fixed identities, recognizing that they are both relational and contextual".

A strong emphasis on identity variants in political institutions tend to repress the particularity of group differences and the heterogeneity of group experiences because the logic which this emphasis generates produces a political climate favouring conformity - cultural and national. In such a climate interrelationability between groups privileges the growth of a national culture over differentiated group cultures which might otherwise co-exist as equals in a form of political parallelism.

\subsection{Recognition and identity}

Like Habermas, Taylor too is concemed with the efficacy of agency. Taylor (1994:75) advocates the practice he calls "the politics of recognition".

The demand for recognition ... is given urgency by the supposed links between recognition and identity. The thesis is that our identity is partly shaped by recognition or its absence, often by the misrecognition of others, and so a person or group of people can suffer real damage, real distortion, if the people or society around them mirror back to them a confining or demeaning or contemptible picture of themselves.

Taylor's politics of recognition is intended to serve as a corrective to a blind spot in plural liberalism. This concerns the impact of power differentials on the distribution of rights. Taylor (1994:81-82) argues that a "discourse of 
recognition" has come to mean two things: pluralist liberals tend to forget that the rights in force at any time in the life of a community have been constituted on the exclusion or subordination of some category of the Other (e.g. gender, race, etc.), and that in consequence a historical gap has arisen between persons able to translate their rights into substantive benefits, and those who have not been able to do so. This is a problem in post-apartheid South Africa which has been unsuccessfully addressed in the current "difference-blind" spaces of our public discourses. The reason for the forgetfulness about historical disadvantage is a consequence of one-level political thinking which recognizes the equal dignity of all citizens, but which accords everyone little more than a formal recognition of rights and other entitlements.

The second meaning has arisen from the interplay between identity and difference as binary oppositions in liberal pluralism. Though an emphasis on difference recognizes identity and distinctness, liberal pluralism has obliterated significant categories of difference in the interests of a (false) monocultural politics, which works on the basis of the "one-level" thinking just referred to. What does it mean to receive equal recognition in the public arena of political life? Taylor's first line of thought begins with the idea that all members of a political community are equally entitled to respect because they are all members of the human race. This line of thought is difference-blind in the right sense. The second line of thought does not reject the ideal of our entitlement to an equality of respect (or dignity), but regards this as itself insufficient. This entitlement needs to be amplified by a (public) recognition of our differences. We are asked to recognize distinct identities, particularly cultural identities, as morally significant categories. Taylor's main argument is that moral identities are formed by recognition. Misrecognition counts as a harm because it deforms identity (women, people of colour, and even people who prefer to live in stone-age technologies, like the Inuit of Canada, are victims of misrecognition). Marginalized groups tend to internalize deformed images of themselves, making deformity a constitutive part of their self-expression.

The second line of thought complements the first, and is seen as a counterweight to the assimilationist tendencies of the first. The first line of thought - the line of equal dignity - champions nondiscrimination and advocates difference-blindness: given any case, no one is entitled to differential treatment unless there are good (publicly defended and accepted) reasons why some particular individual should be treated differently. The second line of thought - the line of unique identity argues that in order to attain a political community in which nondiscrimination is the norm, we need to make distinctions between different cultural communities distinctions which call for differential treatment as morally justified (given the particular history of disadvantaged communities) 
Against liberal pluralist political practice in South Africa

\section{- The line of unique identity}

The line of unique identity identifies two main areas in which the recognition of difference is necessary and differential treatment justified. In some South African communities a great many people have been handicapped by poverty which has reduced their citizen rights to second and even third class status. It does not help to offer these people citizenship rights without social programmes designed to alleviate their poverty and upgrade the status of their citizenship rights. Inherited poverty traps are difficult to overcome and mark a difference which citizen rights itself cannot eliminate. The mere award of citizenship rights is difference-blind in the wrong sense in that it perpetuates a social order in which asymmetrical power relations between rich and poor remain in force. There is, of course, a problem with social programmes designed to alleviate the social conditions of historically disadvantaged groups. Such programmes tend to be assimilationist, i.e. they tend to assimilate disadvantaged groups to the cultural identity of the communities which dominate the political life of the society at large, a fact which tends to reinforce the "inferior" status of the disadvantaged cultures. The politically dominant or hegemonic culture assimilates the particularity of the disadvantaged cultures into a homogeneous mould. In so far as the disadvantaged groups take on an alien form, they lose their particular identities. Their identities are suppressed, and this itself is highly discriminatory and inegalitarian.

Taylor, however, believes that equal recognition will resist this kind of marginalization. For instance, the hegemonic success of the white culture in South Africa was mainly due to the fact that values deriving from the cultural capital of the white culture were falsely presented as universal values. Prior to the demise of apartheid the allegedly universalist status of white values was used as a divisive tool separating white and black and securing political power for the white culture. It is important to note that white values are embedded in white cultures and as such they are particularities, though they have masqueraded as universally valid. There is in this falsehood a lesson to be learnt from the postapartheid era. The difference-blind value structures which have gained pride of place in the current political life of South Africa also claim to be universalist in so far as our capacity for moral action is recognized as a capacity all human beings share. It is thus in virtue of this capacity that all human beings are regarded as deserving equal respect and dignity. This is the right sense of the difference-blind values mentioned above. But we must take care that the wrong sense of difference-blind values do not override the right sense, i.e. do not override the values of particularity, particularly those values associated with our need to be recognized for who we are and where we come from. This capacity for defining one's own identity as one constituted by the identity of one's cultural community must likewise be respected equally in everyone. In this respect it is not enough to recognize that we all have the same potential for moral action; we must also 
guard against the idea that some cultures are more valuable than others, for in entertaining this possibility we deny human equality.

A politics of equal recognition - such as the one being defended here - will be one hospitable to difference because of the following reasons:

- Such a politics does not only insist on uniform entitlements (rights to liberty, freedom from unlawful arrest, equality before the law etc.), but also looks at the worth of these entitlements, particularly for historically disadvantaged communities.

- A politics of equal recognition takes the collective goals of cultural communities seriously, which means recognizing cultural differences and making space in the public (political) forum for these differences in the attempt to construct a common political identity.

\section{Radical democracy: a critique}

\subsection{Mouffe's parallelism}

Mouffe (1992) characterizes parallelism as a kind of political association that can be "enjoyed among relative strangers belonging to many purposive associations [civic communities] and whose allegiances to specific communities is not seen as conflicting with their membership in the civil association" (Mouffe, 1992:233).

This civil association is modelled on Oakesholt's republica, a "practice of civility ... specifying not performances, but conditions to be subscribed to in choosing performances (Mouffe, 1992:232).

Since this form of political association admits a multiplicity of substantive ideas of the common good - embodied in specific civic associations - the conditions at issue here take the form of a "complex of rules" (Mouffe, 1992:32), and identification which encourages the idea of a common bond (rather than a common good) as the ground of a common political identity. Mouffe (1992:235) characterizes this common identity, which is the basis of citizenship, as an "articulating principle" making possible the "different subject positions" of the agent (i.e. different social relations engendered by such categories as gender, class, race, ethnicity, culture etc.) and holding "civic" and "civil" in a state of balance. Civic associations are "private", and the practices and rules of civility are "public", but the two identities of the "decentred" subject "exist in a permanent tension that can never be reconciled" (Mouffe, 1992:238).

This impossibility is the baseline of Mouffe's argument for a genuine parallelism. A multicultural parallelism would require a different conception of the subject one which stresses the constitutive role of a multiplicity of subject positions and a 
Against liberal pluralist political practice in South Africa

multiplicity of social identities. To the extent that such a decentred subject displaces a unitary subject, to that extent the homogeneous unity of national culture would be unable to subvert the identity of different cultural groups (Mouffe, 1992:233). And it is not difficult to see why, for the decentred subject difference is no longer a deficiency or threat and so cannot serve as the basis of cultural oppression or domination - provided, of course, that a genuine parallelism holds sway.

Mouffe's "decentred" self remains effacious in her agency in two ways: the possibility of her agency in one sphere of social life cannot be diminished by her position in another sphere, and membership of the various spheres cannot become mutually exclusive. Two things hold the argument in place: The idea of a decentred self, an "ensemble of subject positions" constructed in the "discursive surfaces" (Mouffe, 1992:237) of public dialogue, and the idea that civic and civil identities - conceptualized as "forms of identification" (Mouffe, 1992:237) resist each other, and therefore create a space for a contested dialogue. Within this dialogue questions about identity and difference can be raised without fear of compromise, without fear of collapsing into binary oppositions on a single scale of assimilation.

These ideas create an interesting point of interaction between Goldberg, Mouffe, Kymlicka and Taylor, in opposition to Habermas's homogenization of culture and politics. Kymlicka's concern with a cultural context as moral category, and Taylor's concern with egalitarian relations between such contexts - based on the humanistic assumption that all cultures have "something important to say to all human beings" (Taylor, 1994:98) - complement Mouffe's efforts at dispelling the idea of a binary opposition between difference and identity. A civil space which can accommodate both identity and difference, again, is a space in which Goldberg's "comparative contextualization" would generate the critical tools needed to sustain values like egalitarian reciprocity, mutual respect and the recognition of difference.

Do the critics of the monoculturalism of modemity sketch a viable alternative? The outstanding feature of Kymlicka's work is the importance he attaches to the condition of constitutiveness. Community is constitutive of the contexts in which choice and identity are nurtured, and this is a good reason for any community to claim the right for the protection of its (collective) cultural identity. The cultural spaces Kymlicka creates in his tapestry of a multicultural politics are (to some unspecified degree) interrelational; they do not freeze or fix identities but rather attempt to contextualize the process of identity formation within and between cultural spaces, in the way Mouffe's views require. Recognition (affirmation) of identity-in-difference - in the sense Taylor requires - which gives to both identity and difference their dues, refrains from forcing membership of any particular 
group on anyone. This too overlaps with Mouffe. Though Taylor sees community as constitutive of identity, interrelationability prevents membership from becoming a limitation on individuals' autonomy. The former South African homelands policy bears witness to the consequences of misrecognition and forced or fixed group membership. Taylor's plea for equal recognition (and equal worth of citizenship) is in line with Kymlicka's recommendations, which are flexible enough to allow systems of cultural membership, but not so flexible as to allow oppression.

Taylor's theme also interacts with Mouffe's concerns. Neglecting differences by focusing too sharply on "equality" leads to assimilation and the loss of the specific identities of communities. Accentuating the specific characteristics of different communities, however, leads to the exaltation of collective identities and the signalization of others as completely Other, i.e. as persons whose cultures are in principle inaccessible. Mouffe (1992:225-239) argues that, given the treatment of "identity" and "difference" as binary opposites a focus on differential treatments and the appropriate social measures that might be implemented as an expression of newly discovered sensitivity to differences, may have the opposite of the intended outcomes viz. assimilation, marginalization and minoritizing. In multicultural societies such outcomes are invited by the identity variant present in the appeal to a collective identity - the equalizing force of the difference-blind values of liberal pluralism which transforms multiplicity into a new uniformity. For Mouffe the most effective counter lies in a reconceptualization of the subject - her idea of "decentred" subject capable of occupying different subject positions. This idea implies a notion of social cohesion quite different from that defended by Habermas. But, since Mouffe does not work this out in any detail, I turn to Ryan (1989) to show what Mouffe's views might entail

\subsection{Ryan's hypothesis for a post-revolutionary society}

In Habermas a unitary culture is premised on the separation of questions of justice (and rights) from questions about the good life, which is a function of the separation of the public and private spheres. Judgements about justice fall within the ambit of the public sphere and are subject to the validating norms of public discourse. Judgements about the good life pertain to the private sphere, and are not open to regulation or interference by the civil authorities. This draws an "inside"/"outside" ("interior"/"exterior") boundary in the psyche of the subject, and in society, but one which allows the public sphere to colonize the private sphere through the validating norms of public discourse

Ryan takes issues with these dichotomies on several counts, but his most pertinent criticism focuses on liberalism's understanding of equality as a formal principle of equal treatment. Briefly, Ryan argues that the liberal ideal of equality is merely a form of juridical equality, which is a consequence of the "public- 
private" distinction. This ideal arises from liberalism principles of rational justice which are developed apart from the "actual material situation of the social world" (Ryan, 1987:168). The consequences of this, as Ryan (1987:168) points out, are unjust.

The ideal of equal treatment then becomes a means of justifying the existence of that particular social situation. If all are treated equally by the law, then the empirical specificities of social inequality can be made to seem legitimate. They are the result of fair play regulated by fair rules or principles. In this scheme, then, the rational principle of equality is the cause of law, and social inequality, rather than being seen as the cause that calls forth the principle of equal treatment as a response, comes to be seen as the secondary effect, an accidental result of essentially fair rules.

The liberal principle of equality of treatment is then not a foundation principle of liberal society, but rather the product of inequality in liberal society - inequality which itself is a function of the "public-private" dichotomy. If this is so, it cannot be assumed that a boundary of the kind in question can be drawn in the same way in all cultures. So if one is to construct a public dialogue around Goldberg's idea of "comparative contextualization", it needs to be borne in mind that where a boundary is drawn is a function of native subjectivity.

As indicated above, the way Habermas draws the distinction between private and public in the psyche of the subject, subjects the "interior" realm - the domain of relations of free association - to the "exterior" realm - the domain of normed public discourse. According to Ryan (1987:20) this intrusion is due to Habermas's view that the labour process is part of the "rational realities of capitalism" (and thus part of the overall project of the rationalization of society), and to the fact that a system like money has not lost its class specificity, thus sustaining a "self-reproducing class system" (Ryan, 1987:29). Ultimately the problem is due to the fact that a doctrine of rights is welded to an individualist model of the social good in which the right to personhood grew up historically in conjunction with the right to property (Ryan, 1987:152). It is not difficult to see what the project of modernity in its liberal pluralist form has in store for South Africa. Money and its concomitant social power differentiations, translated into political power, elevated a white intelligentsia to the status of managers of a capitalist economic system which requires labour exploitation as a necessary and rational feature of its operations. Though this situation was particularly evident during the apartheid era, it grew up during the era of colonialism. It is the problem affirmative action policies are unsuccessfully attempting to grapple with - unsuccessful because, if Ryan is right - modernity's attempts to address the social problems which have developed in the wake of differential patterns of distribution tend to assimilate difference and marginalize historical identities. This is a source of serious social tension. What counts us valid (or fair) for black 
Pieter Coetzee

youths in South Africa today differs greatly from what counts as valid (or fair) for South Africa's white professionals. The concerns (needs, desires) of black youths are for white professionals exactly what their problems are about, and vice-versa. Power differences and their respective inequalities of station make each interpret what counts as valid (or fair) in ways derivable from their respective material circumstances. Modernity's apology for capitalism does not convince everybody that material inequality should be deemed morally acceptable.

Ryan advocates a reconceptualization of liberalism's principles of liberty and equality. Mouffe's "decentred self", and Ryan's "complex of differential boundary relations", tie selfhood to the external social world in such a way that a demarcation between "interior" and "exterior" becomes impossible. There is no space for a non-relational self, and by implication, no space for non-relational action in civic or civil society. The self, then, ceases to be an owner for whom rights are property. The formal right to equal treatment, for instance, becomes inseparable from its institutional context and the "interrelational character of social wealth" (Ryan, 1987:117) and hence inseparable from material equality So the doctrine of rights become a doctrine of "exercisable rights" (Ryan, 1987:162). Two consequences of socio-psychological significance follow. The first is that the white professionais' right to own large quantities of property - a right gained in a context in which white economic power diminished participation by blacks - becomes the subject of social critique: in Mouffe's (1992:236) words their "existing rights have been constituted on the very exclusion or subordination of the rights of other categories", and are therefore open to radical reinterpretation. The second is that, to the extent black youths are able to claim more exercisable rights, to that extent their identity would cease to be abridged in comparison with their white counterparts.

\section{What might we gain from Goldberg's "comparative contextualization"?}

There is no doubt that new identities are required (reconstitution of historical identities?). Mouffe favours a "common political identity" as "radical democratic citizens" (Mouffe, 1992:236) which centres in a reinterpretation of the principles of liberal-democratic cultures - one which takes account of "the different social relations and subject positions in which ... [the principles of liberty and equality] are relevant: gender, class, race, ethnicity, sexual orientation etc." (Mouffe, 1992:236).

- There is also no doubt that new institutional structures are required. Social relations in which relations of domination prevail must be challenged if the principles of liberty and equality are to be reconceptualized and their import rewritten. What is needed here is a conception of "democratic equivalence" (Mouffe, 1992:236), a conception of citizenship focused on a common 
identification with reinterpreted principles of liberty and equality - and one allowing the construction of a "we" (Mouffe, 1992:230) from our diversity, which leaves difference intact.

- There is no doubt that the political and moral force of culture should be recognized and given pride of place in the democratic culture of the new South Africa.

\section{References}

ALVERSON, H. 1978. Mind in the heart of darkness: Value and self-identity among the Tswana of Southern Africa. New Haven : Yale University Press

BENHABIB, S. 1992. Situating the self. Cambridge : Polity Press

BUCHOWSKI, M. 1979. The shifting meanings of civil and civic society in Poland (In Hann, C. \& Dunn, E. eds Civil society. London : Routledge. p. 79-98.)

FISHMAN, J 1972 The sociology of language: an interdisciplinary social science approach to language in society. Massachusetts : Newbury House Publishers.

GOLDBERG, P T ed 1994. Multiculturalism Oxford : Blackwell

HABERMAS, J 1979. Communication and the evolution of society. Translated by $T$ McCarthey. Boston : Beacon

KYMLICKA, W 1989 Liberalism, community, and culture. Oxford : Clarendon Press

MALOBA, W O 1993 Mau-Mau and Kenya: An analysis of peasant revolt. Indianapolis : Indiana University Press

MILLER, D 1989. Northeastern Kenyan riverine farmers in conflict with colonial development strategies. ( $n$ Linnebuhr, E. Transition and continuity-identity in East Africa and beyond: In memoriam of David Miller. Bayreath : Breitinger p. 353-368.)

MKHWANAZI, F, 1985. Apartheid's long winter sunset. National Student, 82(1) 1-18

MOON, J.P. 1993. Constructing community. Princeton : Princeton University Press

MOUFFE, E. 1992. Democratic citizenship and the political community. (In Mouffe, E. ed Dimensions of radical democracy. London: Versa. p. 225-239.)

PETERS, M 1995. Radical democracy, the politics of difference, and education (In Kanpol, B \& McLaren, P. eds Critical multiculturalism. Westport : Bergin and Garvey. p. 3957.)

PUSEY, M 1987. Jurgen Habermas reason and the evolution of culture (In Austin-Broos, D J. Creating culture London: Allen \& Unwin. p 194-209.)

RYAN, M 1989. Politics and culture: Working hypothesis for a post-revolutionary society London : MacMillan

SENSAT, J.. 1979. Habermas and Marxism. London : Sage Publications.

TAYLOR, C. 1994. The politics of recognition. (In Goldberg, P T ed Multiculturalism Oxford Blackwell p. 75-106.)

WILSON, Monica \& THOMPSON, L. eds 1975. The Oxford history of South Africa Cape Town : Oxford University Press 